\title{
Possibility of Dissolution and Removal of Thick Pus due to the Physical-Chemical Characteristics of the Medicines
}

\author{
Aleksandr Urakov ${ }^{1,2}$, Natalia Urakova ${ }^{1}$ and Leisan Chernova ${ }^{1}$ \\ 1. Department General and Clinical Pharmacology, Izhevsk State Medical Academy, Izhevsk 426034, Russia \\ 2. Department of Thermal Deformation Processes, Institute of Mechanics of the Ural branch of RAS, Izhevsk 426067, Russia
}

Received: November 05, 2013 / Accepted: November 20, 2013 / Published: November 25, 2013.

\begin{abstract}
This paper presented the dynamics of the rheological properties of dense pus after mixing it with solutions plasma substitutes and antiseptics with respect to physical and chemical factors of the local interaction. It was studied the effect of the following factors: gravity, specific gravity, temperature, turbulence, strength, internal pressure, carbonation, $\mathrm{pH}$, osmotic activity, the total concentration of ingredients, the surface activity and the amount of medication. It was found that rheology of liquid, viscous and dense biological tissues may improve medicines having the following physicochemical characteristics: hypertermia, high alkaline, high turbulence and high saturation by gas. Found that the leaders of improving rheology medicines and biological tissues are sodium bicarbonate, hydrogen peroxide and carbon dioxide, introduced in medecines similar carbonated beverages. The data allowed to develop a new hygienic medicines designed to liquefy thick purulent masses in patients with pleural empyema, peritonitis, rhinitis, sinusitis, conjunctivitis, tearful stones, osteomyelitis and sulfur tubes. New sanitary preparations are heated to $39-42{ }^{\circ} \mathrm{C}$ aqueous solutions $0.5 \%-10 \%$ sodium bicarbonate, $0.5 \%-3 \%$ peroxide of hydrogen and carbon dioxide, which is entered into the solution at a pressure of 0.2 ATM.
\end{abstract}

Key words: New medicines, hygiene products, pus diluting agent, physical-chemical properties.

\section{Introduction}

Infection of the upper respiratory tract, gastrointestinal tract, organs of vision and other parts of the body, often accompanied by the appearance in them of thick and sticky pus, which impairs the health of the sick, delaying the onset of his recovery, and is the cause of the infection of blood and a source of infection to others [1]. Therefore, the patients and medical staff want to get rid of pus and delete it out.

However, few people can quickly and safely remove the pus, because on the one hand, the pus is usually thick and very sticky mass, firmly glued to the surface of the body, and on the other hand, in the world there

Corresponding author: Aleksandr Urakov, M.D., professor, research fields: phisical-chemical, pharmaceutical, pharmacology and engineering. E-mail: urakoval@live.ru. are still no special medicines for dissolving thick pus, allowing time to destroy all of pus, to deprive him of viscosity, stickiness and turn it into an easy flowing liquid [2, 3]. Moreover, today for the removal of dead tissue there are not special medicines, solvent thick pus, and this purpose apply the most common medications such as drinking water, hypertonic solution of sodium chloride and for other "normal" liquids (in particular, the solutions of antiseptic funds and substitutes plasma) [4]. And many of them do not destroy not only pus, but a "delicate" biological tissue like blood $[5,6]$.

In addition, medical staff does not control and does not take into account the dynamics of rheology purulent masses upon introduction of the medicines and conventional technologies washing of wounds and cavities are not based on physical and chemical factors 
of local interaction of applied solutions medicines with pus [7-10]. So there are no new technology liquefaction thick and sticky pus, dramatically increase the efficiency remove thick and solid festering mass $[5,6]$.

At the same time, in recent years we have received evidence of the dependence of the rheological properties of the tear «stones», ear wax, blood clots, clots and blood stains from such physical and chemical characteristics of the drug, as the value of the volume, temperature, acidity (alkalinity), osmotic pressure, concentration, thickness and saturation of solutions by gases [11-22].

In this regard, the aim of our study was to investigate the peculiarities of rheology thick and sticky pus and interstitial diffusion in it solutions of medicines with regard to their temperature, $\mathrm{pH}$, internal pressure and oxygen content and/or carbon dioxide.

\section{Materials and Methods}

Studied rheology pus patients with purulent peritonitis, purulent conjunctivitis and tuberculosis of the lung and pleura. Rheology of pus explored by the eye of in vivo and in vitro before and after the introduction in pus solutions of medicines with regard to the volume of interacting masses, the duration of their interaction, gravity, specific gravity (density), temperature, $\mathrm{pH}$ and osmotic [1, 3, 4]. Studied microstructure of pus as his strokes. Pus was taken for analysis before and after 15 minutes after the start of its interaction with plasma substitutes solutions and antiseptic funds. Smears were prepared and similarly stained smear of blood on standard laboratory methods of dyeing $0.5 \%$ paint Mine-Gryunval prepared by $96^{\circ}$ ethyl alcohol, and paint Romanovsky-Giemsa. The temperature is determined by infrared thermography with the help of thermal imager NEC TH91XX (USA), with the subsequent processing of information by means of programmes Thermography Explorer and Image Processor. Osmotic activity of aqueous solutions defined with cryoscope using vapor-pressure osmometer brand OSMOMAT-030 RS production company ANSELMA Industries (Austria). PH (alkalinity) solutions and purulent masses defined with strips of the universal indicator paper company Lachema. Visualization of gas bubbles in carbonated solutions held in visible spectrum of radiation on the eyes and ultrasound method using an ultrasound device “ALOKA SSD-ALPHA 10" using convection sensor with a frequency of 3 to $7 \mathrm{MHz}$.

\section{Results and Discussion}

Purulent mass extracted from the pleural cavity of patients with pleural empyema, had the consistency of an opaque, formless, thick, viscous and sticky mass of yellow-grey. The microstructure of the pus was a relatively homogeneous and moderately transparent intercellular environment with rarely placed in it opaque cells, half of which was located in isolation from each other, and the other half are closely adjoined to each other, forming groups, including 2-9 cells.

After placing a thick pus and known plasma substitutes and sanifying liquids in laboratory test tubes equal amount of servings at a temperature of 24 or $37{ }^{\circ} \mathrm{C}$ pus was always located at the bottom of the tubes and liquids is always located above the pus. In particular, boiled water, tap water, water for injection, solution $0.9 \%$ sodium chloride solution, a solution $5 \%$ glucose, solution $20 \%$ glucose, solution $40 \%$ glucose, solution $10 \%$ sodium chloride, solution $10 \%$ sodium sulfatsil, solution $20 \%$ sodium sulfatsil, solution $0.02 \%$ furatsilin, solution $0.5 \%$ chlorhexidine, solution $70 \%$ ethyl alcohol and solution 1\% sodium hydrocarbonate were always on top and not mixed with pus during $15 \mathrm{~min}$ of observation. Therefore, rheological properties and other physical and chemical characteristics of pus not changed.

Slight decrease in the viscosity of dense purulent mass and change pus microstructure through 15 minutes of interaction with these solutions happened only when heated to $42{ }^{\circ} \mathrm{C}$. Pus in smears prepared after the interaction with "hot" drugs, looked diluted with large quantities of "islands" of pus, which 


\section{Possibility of Dissolution and Removal of Thick Pus due to the Physical-Chemical Characteristics of the Medicines}

preserved its original structure. Parts of unchanged pus had different sizes and different irregular shape with uneven partially blurred edges and looked isolated from each other due to the fact that around them unevenly and irregularly were placed layers of translucent turbid liquid.

Then we have defined the indicators for the acidity of water and solutions of antiseptics and plasma substitutes. The obtained results showed that all of them except solution of $4 \%$ sodium bicarbonate and solutions of $10 \%$ and $20 \%$ sodium sulfatsil are have a $\mathrm{pH}$ below 7.0, and so are acidic. In particular, indicators of acidity of tap water, boiled water, water for injection, solution furatsiline 1:500, solution of $3 \%$ hydrogen peroxide, solutions $0.9 \%$ and $10 \%$ of sodium chloride are the $\mathrm{pH}$ range of 5.0-6.0, and the performance of the acidity of solution of $0.25 \%$ novokaine and solutions $5 \%, 20 \%$ and $40 \%$ glucose are in the $\mathrm{pH}$ range of 2.7 to 4.0 (Table 1).

In the next series of experiments in vitro at a temperature of $24{ }^{\circ} \mathrm{C}$ we studied the change of rheology and microstructure of thick pus throught 15 minutes after administration in pus water or water solutions of medicines after preliminary artificial amplification acidification to $\mathrm{pH} 2.0$ or alkalinity to $\mathrm{pH}$ 12.0 by introducing them accordingly hydrochloric acid or sodium hydroxide. Our results showed that only alkalization decreases viscosity and dense microstructure purulent masses.

So, after 15 min after injection in a vial with thick, purulent mass of an equal volume of one of the following "hyperacid" liquids (they all have a $\mathrm{pH}$ 2.0) water for injection or water solution of one of the following means: $0.9 \%$ or $10 \%$ sodium chloride solution, $10 \%$ or $20 \%$ sulfatsil sodium, $0.02 \%$ furatsilin or $0.5 \%$ chlorhexidine, purulent masses remain practically unchanged: thick, viscous, sticky and viscous. At the same time, $15 \mathrm{~min}$ after the infusion tube with thick, purulent mass of an equal volume of one of these liquids with a $\mathrm{pH}$ value of 12.0, i.e., accepted property high alkaline, viscosity festering mass is reduced several times. The tough, thick and sticky pus turns into a liquid with a good fluidity.

In parallel, we studied the features of thinning and removal of thick and sticky pus under the influence of water and water solutions of medicines in the conditions of increased their turbulence, which was reached by heating and mechanical wobbled from side to side model cavity (test tube), filled commensurate amounts of pus and one of the investigated solutions. It is shown that the continuous rocking from side to side tubes with interacting environments, namely, with pus

Table 1 Values of $\mathbf{p H}$ of the water and of water solutions of modern antiseptic funds and plasma substitutes.

\begin{tabular}{|c|c|c|c|}
\hline \multicolumn{2}{|c|}{ No. Liquid medication } & \multirow[t]{2}{*}{ Manufacture, Series No.. } & \multirow{2}{*}{$\begin{array}{l}\mathrm{pH} \\
5.95 \pm 0.11^{*}\end{array}$} \\
\hline 1 & Tap water & & \\
\hline 2 & Drinking water from the kettle & & $6.05 \pm 0.07 *$ \\
\hline 3 & Water for injection in vials of $2 \mathrm{ml}$ & SE “Lvivdialect” Series No. 1151205 & $5.02 \pm 0.08 *$ \\
\hline 4 & Solution $0.9 \%$ sodium chloride for injection, $200 \mathrm{ml}$ & JSC “Galichpharm” Series No. 300604 & $5.34 \pm 0.04^{*}$ \\
\hline 5 & Solution $10 \%$ sodium chloride for external use $200 \mathrm{ml}$ & Pharmacy No. 131 (Izhevsk) & $6.05 \pm 0.09 *$ \\
\hline 6 & Solution furacillin 1:5000 & Pharmacy No. 131 (Izhevsk) & $5.70 \pm 0.10^{*}$ \\
\hline 7 & Hydrogen peroxide $3 \% 40 \mathrm{ml}$ & LLC “Ватхэм-pharmacy” Series No. 841101 & $5.45 \pm 0.25 *$ \\
\hline 8 & Solution $5 \%$ glucose for injection $500 \mathrm{ml}$ & JSC “Biosynthesis" Series No. 48102000 & $4.05 \pm 0.09 *$ \\
\hline 9 & Solution $20 \%$ glucose for injection $500 \mathrm{ml}$ & "Novosibirskpharm" Series No. 30703 & $3.50 \pm 0.15^{*}$ \\
\hline 10 & Solution $40 \%$ glucose for injection $500 \mathrm{ml}$ & JSC “Dalhimpharm” Series No. 210101 & $2.70 \pm 0.07 *$ \\
\hline 11 & Solution $0,25 \%$ novokaine for injection $500 \mathrm{ml}$ & Pharmacy No. 131 (Izhevsk) & $4.05 \pm 0.03 *$ \\
\hline 12 & Solution $10 \%$ sodium sulfatsil $10 \mathrm{ml}$ & $\begin{array}{l}\text { FSUE "Moscow Endocrine Factory" Series No. PN } \\
001084 / 01\end{array}$ & $7.90 \pm 0.10^{*}$ \\
\hline 13 & Solution $20 \%$ sodium sulfatsil $10 \mathrm{ml}$ & $\begin{array}{l}\text { FSUE "Moscow Endocrine Factory" Series No. PN } \\
001084 / 05\end{array}$ & $8.30 \pm 0.15^{*}$ \\
\hline 14 & Solution $4 \%$ sodium bicarbonate $200 \mathrm{ml}$ & Pharmacy No. 131 (Izhevsk) & $8.20 \pm 0.09 *$ \\
\hline
\end{tabular}

Note: * $-\mathrm{P}<0,05, \mathrm{n}=5$. 
and high alkaline liquids (water for injection, solutions $0.9 \%$ and $10 \%$ sodium chloride, $10 \%$ and $20 \%$ sulfatsil the sodium, $0.02 \%$ furatsilin at $\mathrm{pH} 12.0$ ), causes continuous reciprocal progressively offset medicated fluid, which is the top layer, with respect to the stationary mass of thick pus, which is the lower layer) and accelerates the process of liquefying of pus on the boundary separating the media. Herewith, the shorter the time interval between the beginning of the interaction and the onset time of removal of the main mass of pus at a temperature of $24{ }^{\circ} \mathrm{C}$ and $42{ }^{\circ} \mathrm{C}$ in 4 and 5 times, respectively, compared with the control (in terms of their physical immobility).

However, it appeared that artificially supported for $30 \mathrm{~min}$ increased turbulence of one of the above solutions do not lead to absolutely complete dissolution of the entire mass of pus.

So, the above means not possess the ability to effectively dilute thick pus are not able to significantly change its rheology and therefore cannot claim the status of medicines for dissolving thick pus. However, such physical-chemical characteristics of the local drug interactions with pus, as hyperthermia, high alkalinity and high turbulence may underlie nonspecific the ability of medicines to dissolve thick pus. In particular, the local hyperthermia not only thins pus, but additionally soften other tissues, stimulates metabolism, inflammation and speeds up the healing of trophic ulcers [23].

To check the value of high alkalinity activity of the solutions we have studied rheology thick pus under the influence of such famous alkaline drugs like solutions of $4 \%$ and $10 \%$ sodium bicarbonate $(\mathrm{pH} 8.0$ and 8.0 ) and solutions of $2.4 \%$ and $24 \%$ aminofillin (pH 9.0 and 12.0, respectively). Originally experiments were conducted at a temperature of $24{ }^{\circ} \mathrm{C}$ in vitro at a relative immobility of the interacting environments (with fixed test tubes containing equal amounts of interacting environments) is similar to the above experiments. Our results showed that after $15 \mathrm{~min}$ of interaction of each of these solutions with thick pus, pus completely lost their viscosity and became liquid and very fluid. Solution of $10 \%$ sodium bicarbonate has the highest ability to dissolve thick pus.

To check the value of hyperturbulence and hyperthermal activity of the solutions we have studied rheology thick pus under the influence of solution of $4 \%$ sodium bicarbonate in conditions of continuous swinging tube containing equal amounts of interacting environments, 24, 37 and $42{ }^{\circ} \mathrm{C}$. Found that full liquefaction pus occurred at a temperature of $24{ }^{\circ} \mathrm{C}$ for $15 \mathrm{~min}$, at a temperature of $37^{\circ} \mathrm{C}$, through of $12.5 \mathrm{~min}$, and at a temperature of $42{ }^{\circ} \mathrm{C}, 12 \mathrm{~min}$ of interaction. After thinning pus became lighter and acquired the form of a homogeneous semi-transparent environment. Microstructure of liquefied pus differed predominant presence of a homogeneous transparent environment with rarely arranged single and group cellular elements.

Then we explored a range of specific weight, osmotic and acid activity of purulent masses obtained in patients with purulent peritonitis, purulent pleuritis, purulent conjunctivitis, purulent rhinitis and purulent abscesses. The obtained results showed that all the festering mass is a relatively heavy, isotonic and acidic biomass with a specific gravity within $1.030-1.040 \mathrm{~g} / \mathrm{cm}^{3}$, with osmotic activity within $280-300 \mathrm{mOsmol} / 1$ of water and acid activity within the pH 5.8-6.2.

Following this was defined specific weight we used liquids. They all have specific gravity of less than $1.30 \mathrm{~g} / \mathrm{cm}^{3}$, except for the solution of $10 \%$ sodium chloride and solution $10 \%$ sodium bicarbonate. The extensive research has shown that the solutions of sodium bicarbonate in concentrations above $4 \%$, have specific weight, exceeding $1.040 \mathrm{~g} / \mathrm{cm}^{3}$ (meaning that they are be "heavier" than the "heaviest" pus), pH 8.0 (that is, are alkaline) and osmotic activity above $450 \mathrm{mOsmol} / 1$ of water (i.e., are weak hypertonic solutions).

These data allowed to explain why purulent mass sink in water and in solutions with total concentration 
of ingredients of less than $3 \%$, as well as to suggest that the festering mass will float up. Our studies have confirmed this assumption. Solution $4 \%$ sodium bicarbonate is able to sink in purulent masses and is capable under the force of gravity implemented in thickness of purulent masses [2].

Consequently, the high dense, high alkalinity and high osmotic activity, that is inherent in a solution of $4 \%$ sodium bicarbonate, ensures a high ability to dilute thick pus. In addition, as shown by our results, ability to dissolve thick pus of this solution can be enhanced by high temperature and high turbulence [9].

It is clear that the maximum permissible hyperthermia can be given a solution to its simple heating up to $42^{\circ} \mathrm{C}$, but the maximum high turbulence needed to accelerate the process of liquefaction and dispersion of pus, cannot be achieved by «manual» jiggle the capacity of interacting environments from side to side. Therefore to give a solution of the maximum possible, turbulence decided to increase the concentration and the pressure of gases, in particular, due to carbon dioxide similarly carbonated mineral water and due to the hydrogen peroxide. We hypothesized that the high saturation by gas of the solution $4 \%$ sodium bicarbonate will have a powerful aggressive action on pus, because warm, heavy, alkaline and high osmotic action of solution is to be able to intensively penetrate into a pus and high saturation solution by gas and rapid formation of bubbles of carbon dioxide within a pus is to be able to blasting it from the inside.

To verify this assumption, we initially added in a solution of $4 \%$ sodium bicarbonate carbon dioxide under excessive pressure of $0.2 \mathrm{ATM}$. Infusion of the solution at a temperature of $42{ }^{\circ} \mathrm{C}$ in a test tube with a festering mass withdrawn from the pleural cavity of a patient suffering purulent pleural empyema, led to the rapid formation of purulent foam and for the expulsion of tubes almost all purulent mass. Also intensively formed purulent foam that was thrown out of the tube as a geyser. Found that high turbulence and high saturation by gas of warm solution of $4 \%$ sodium bicarbonate gives him ability to effectively and safely disposed of pus out of purulent fistula when pancreatic necrosis [24].

It also found that high saturation by carbon dioxide of solution $0.9 \%$ sodium chloride provides visualization using ultrasound vector direction and speed of movement of streams of a solution into the abdominal cavity is closed when it is flushed with the conditions of purulent peritonitis by identifying and monitoring of the movement of bubbles of carbon dioxide. In addition, it is shown that the visualization of ultrasound move process of gas bubbles in a moving solution of $0.9 \%$ sodium chloride in the abdominal cavity allows you to monitor and change the flow of a fluid due to changes in the location of the patient's torso in space together with a cavity. The point is that changing the location of the torso and abdomen in space allows you to change the direction of fluid in the abdominal cavity, necessary to wash better chosen site. The ultrasound provides visualization move the liquid on the change of movement of gas bubbles [25].

Then instead of the carbon dioxide we added to a solution of $4 \%$ sodium bicarbonate $3 \%$ hydrogen peroxide. After this has been studied piolytical activity of this solution when heated to a temperature of $42{ }^{\circ} \mathrm{C}$ and introduction in the tube with pus. It turned out that infusion into a test tube with a thick pus equal amount of warm solution of $4 \%$ sodium bicarbonate and $3 \%$ hydrogen peroxide at a temperature of $42{ }^{\circ} \mathrm{C}$ leads to 5 min to complete transformation of two interacting environments in one turbid liquid with fluid properties. Microstructure diluted pus looked as much a divorced transparent colloid extracellular environment with "cleansed" cellular elements united in groups of up to 20 cells.

Found that warm solution of sodium bicarbonate and hydrogen peroxide has the ability to improve the rheology of thick pus by its dilution. Intensive liquefaction cancer occurs under the influence of hyperthermia, hyperalkalinity, hyperdense and 
hyperturbulence solution. In this case the solution is alkaline burn intercellular colloid environment catalyzed by its heating and interstitial boiling (blowing). Alkaline burn intercellular colloid environment thins clot due to the hydrolysis of proteins and saponification of fats that accelerates heat and intense "blowing" of pus on the boundary separating the media through the formation of bubbles of oxygen from the hydrogen peroxide under the influence of the enzyme catalase.

\section{Conclusions}

It is shown that the rheology of thick pus and solutions of antiseptics and substitutes plasma at their local interaction more just depends on conformity of volume and concentration, density, temperature, alkaline, osmotic and turbulent activity of medicines. Found that a leader in improving fluidity dense festering mass is solution of $4 \%$ sodium bicarbonate, heated to $42{ }^{\circ} \mathrm{C}$ and hypergazation due to the introduction of $3 \%$ hydrogen peroxide or by introduction of carbonic gas under high pressure of 0.2 ATM. It is shown that hypergazation so warm solution of $4 \%$ sodium bicarbonate acquires high piolotic activity due to the following physical and chemical characteristics: hyper-thermi, hyper-alkalinity, hyper-density and hyper-turbulence. The obtained results have allowed to develop a new sanitary medicines, liquefying and remove thick purulent masses in introducing empyemas pleura, to remove festering mass of purulent fistula when pancreatic necrosis, controlled and managed by peritoneal dialysis at purulent peritonitis, for washing conjunctival cavity with purulent conjunctivitis, for the treatment of trophic ulcers and for the dissolution of the tear stones, as well as to liquefy and remove ear wax from the ear [6, 21-27].

\section{References}

[1] N.A. Urakova., A.L. Urakov, V.A. Chereshnev, N.A. Mihailova, V.B. Dementyev, A.Yu. Tolstolutsky, Hypergazation, hyperbarometric pressure, hyperosmolarity, hypertermition, hyperalkalization and high surface activity solution as factors increasing its washing activity, Chemical Physics and Mesoscopy 3 (2007) 256-262.

[2] N.A. Urakova, A.L. Urakov, N.A. Mihailova, A.Yu. Tolstolutsky, A.P. Reshetnikov, T.V. Gavrilova, et al., Heated up to $42{ }^{\circ} \mathrm{C}$ and saturated sodium bicarbonate solution $3 \%$ hydrogen peroxide-leader for liquefaction thick and sticky pus, Medical Care 1 (2009) 46-48.

[3] V.B. Dementiev, A.L. Urakov, N.A. Urakova, N.A. Mihailova, N.V. Sokolova, A.Yu. Tolstolutsky, et al., Erosion of the pathological biological agent at its expansion, heating and alkalization, Chemical Physics and Mezoscopy 11 (2009) 229-234.

[4] A.L. Urakov, N.A. Urakova, B.G. Jushkov, N.A. Zabokritsky, M.Yu. Gauskhneht, Hypertermition, hypergasation and hyperalkalisation solutions as factors piolytical activity, Bulletin of Ural Academy of Medical Sciences 1 (33) (2011) (84-87).

[5] Modern Problems of Science and Education Home page, http://www.science-education.ru/107-7607 (accessed Mart 8, 2013).

[6] A.L. Urakov, N.A. Urakova, V.A.Chereshnev, M.V. Chereshneva, T.V. Gavrilova, A.Yu. Tolstolutsky, et al., Tool to thin thick and sticky pus, Invention, RU Patent 2360685 C2 (2009).

[7] A.L. Urakov, N.A. Urakova, N.A. Mihailova, A.P. Reshetnikov, V.I. Shahov, Local post injection aggressiveness of solutions of medicines in indurated tissues and ways of its elimination, Med. Almanac 1 (2007) 95-97.

[8] Modern Problems of Science and Education Home page, http://www.science-education.ru/104-6687 (accessed May 7, 2012).

[9] Modern Problems of Science and Education Home page, http://www.science-education.ru/105-6812 (accessed May 20, 2012).

[10] Modern Problems of Science and Education Home page, http://www.science-education.ru/107-8171 (accessed Feb. 17, 2013).

[11] A.L. Urakov, N.A. Urakova, B.E. Novikov, A.V. Boyarintseva, L.F. Gaisina, Antiseptic ear drops with piolytical activity, The Recipe 6 (80) (2011) 26-31.

[12] A.L. Urakov, B.E. Novikov, B.G. Jushkov, N.A. Urakova, L.F. Gaisina, Hygienic "ear drops" and safe way to remove ear wax from the ear, Ural Medical Journal 6 (2011) 142-145.

[13] N.A. Urakova, A.L. Urakov, Spotted multicolored skin on the buttocks, thighs and arms patients as page stories "injectable disease", Successes of Modern Natural Sciences 1 (2013) 26-30.

[14] A.L. Urakov, N.A. Urakova, Thermography of the skin as 
a method of increasing local injection safety, Thermology International 23 (2) (2013) 70-72.

[15] A.L. Urakov, Cold in protection for the heart, Successes of Modern Natural Sciences 11 (2013) 32-36.

[16] A.L. Urakov, The recipe on the temperature, Science and Life 9 (1989) 38-42.

[17] A.L. Urakov, A.P. Kravchuk, Temperature regime of the wound surface as a factor of hemostasis, Military-Medical J. 8 (1991) 65-66.

[18] A.L. Urakov, Hyperthermia and ischemia as factors of hemostasis, Successes of Modern Natural Sciences 12 (2013) 8-12.

[19] Fundamental research Home page, www.rae.ru/fs/?section=content\&op=show_article\&articl e id $=10001589$ (accessed Oct 15, 2013).

[20] A.L. Urakov, N.A. Urakova, A.A. Kasatkin, Local body temperature as a factor of thrombosis, Thrombosis Research, Suppl. 1 (131) (2013) S79.

[21] A.L. Urakov, N.A. Urakova, T.V. Urakova, A.Ya. Malchikov, A.A. Kasatkin, et al. The way the cubital vein catheterization and multiple intravenous injection of drugs, Invention, RU Patent, 2387465 C2 (2010).

[22] A.P. Reshetnikov, A.L. Urakov, N.A. Urakova, N.A.
Mihailova, M.V. Serova, I.V. Elhov, et al., The method to express remove blood stains from clothes, Invention, RU Patent, 2371532 C2 (2009).

[23] N.S. Strelkov, A.L. Urakov, A.P. Korovjakov, N.A. Urakova, A.P. Kravchuk, M.V. Korepanova, et al., The method of treatment of long-term psychological wounds, Invention, RU Patent, 2187287 C2 (2002).

[24] A.V. Chereshnev, N.S. Strelkov, A.L. Urakov, N.A. Mihailova, N.A. Urakova, V.V. Vatulin, et al., Hyper-gazation and hyper-osmotic antiseptic, Invention, RU Patent, 2331441 C2 (2008).

[25] V.A. Chereshnev, N.S. Strelkov, A.L. Urakov, N.A. Mihailova, N.A. Urakova, Method of peritoneal dialysis from fizzy solution, Invention, RU Patent, 2336833 C2 (2008).

[26] A.L. Urakov, N.A. Urakova, I.V. Otvagin, N.S. Strelkov, V.E. Novikov, B.G. Jushkov, et al., The way and means to remove sulphuric tube, Invention, RU Patent, 2468776 C2 (2012).

[27] L.B. Bondarenko, A.L. Urakov, V.E. Novikov, N.A. Zabokritsky, A.V. Vinogradov, M.L. Kashkovsky, et al., Multifunctional solution for epi-bulbar instillation, Invention, RU Patent, 2452478 C2 (2012). 